\title{
Research on the Route Choice of the Urban Rail Transit Network based on the Imperialist Competitive Algorithm
} \author{
Ye Lu ${ }^{\mathrm{a}}$, Lian XiaoFeng ${ }^{\mathrm{b}}$,Wang Yan $^{\mathrm{c}}$ and Zhang DanYao ${ }^{\mathrm{d}}$ \\ School of Computer and Information Engineering, Beijing Technology and Business University, \\ Beijing, China \\ aYelu@th.btbu.edu.cn, 'Lianxf@th.btbu.edu.cn, 'Wangy@th.btbu.edu.cn, ${ }^{\mathrm{C}} \mathrm{ZDY} @$ th.btbu.edu.c
}

Keywords:urban rail transportation, route choice, ICA algorithm, optimization.

\begin{abstract}
In order to improve the rationality of the route choice for passengers' travel, this paper presents an optimization method of the route choice for urban rail transit network based on the imperialism competition algorithm (ICA). The experiment results show that the proposed method is feasible and the algorithm is effective.
\end{abstract}

\section{Introduction}

Urban rail transit hasbecame one of the main ways to alleviate traffic congestion. Due to the complexity of urban rail transit, it is very important to choose the optimal route efficiently among the many paths.

There are many optimization algorithms for route choice. In 2011, Liu Xu proposed the ant colony algorithm to solve the rail transit route selection model [1]. 2013, Cheng Bo et al. build a large road transport path selection optimization model [2]. Liu JianFeng et al. analyzed the passenger routechoice behavior to construct a generalized travel cost function model[3]. Here,the ICA algorithm is used to solve the route choice model of the urban rail transit. In 2007, Atashpaz-Gargari and Lucas [4] proposed a socio-political evolutionary algorithm, called the ICAalgorithm. In 2014, Hao Yan [5] takes the ICA to non-probabilistic reliability analysis . In 2016, Shao YongLiang [6] has proposed a method for solving the structural modal parameter identification by the ICA.

Aiming at the problem of route choice in urban rail transit, this paper proposes an algorithm based on ICA, and the experimental results show its effectiveness.

The rest of paper is organized as follows. In section 2, we present the route choicemodel; following that in section 3, we discuss thatthe optimal route determination based on the ICA. Section 4 is mainly about Experiment and result analysis. Finally, we discuss about conclusion in section 5.

\section{II. route choice model}

\section{A Generalized travel cost model}

Establishing the generalized travel cost model of rail transit:

$$
\begin{gathered}
\mathrm{U}\left(\mathrm{F}_{\mathrm{T}_{\mathrm{R}}}, \mathrm{F}_{\mathrm{T}_{\mathrm{T}}}, \mathrm{F}_{\mathrm{M}}, \mathrm{F}_{\mathrm{Q}}\right)=\beta_{1} \mathrm{~F}_{\mathrm{T}_{\mathrm{R}}}+\beta_{2} \mathrm{~F}_{\mathrm{T}_{\mathrm{T}}}+\beta_{3} \mathrm{~F}_{\mathrm{S}}+\beta_{4} \mathrm{~F}_{\mathrm{Q}} \\
\text { s.t. } \beta_{1}+\beta_{2}+\beta_{3}+\beta_{4}=1 \\
\beta_{1}, \beta_{2}, \beta_{3}, \beta_{4} \geq 0
\end{gathered}
$$

Where, $\beta_{1}$ represents the weight coefficient of the vehicle time cost, $\beta_{2}$ refers to the weight coefficient of the transfer time cost, $\beta_{3}$ is the weight coefficient of the transfer distance cost, and $\beta_{4}$ means the weight coefficient of the congestion time cost:

$$
\beta_{i}=\frac{P_{i}}{P_{1}+P_{2}+P_{3}+P_{4}}
$$

Here, $P_{1}, P_{2}, P_{3}, P_{4}$ are the ratio of the travel time, the transfer time, the transfer distance, and the congestion degree as the influencing factors of the route choice respectively.

Here, we use the number of transfers as the constraint of path selection,as the following : 
Where, $M=4$.

$$
\operatorname{minU}\left(\mathrm{F}_{\mathrm{T}_{\mathrm{R}}}, \mathrm{F}_{\mathrm{T}_{\mathrm{T}}}, \mathrm{F}_{\mathrm{S}}, \mathrm{F}_{\mathrm{Q}}\right)
$$

$$
\text { s.t. } \mathrm{m} \leq \mathrm{M}
$$

\section{III. optimal route determinationbased on the ICA}

\section{AInitialization}

The function value of the country is denoted by $N_{\text {country. }}$. Where, the n country The fitness is defined as follows:

$$
\mathrm{c}_{\mathrm{i}}=\sum_{k=1}^{n}\left(u_{k}(i) / \sum_{i=1}^{N_{\text {rank }}} u_{k(i)}+2(\operatorname{rank}(i)-) 1\right)(4)
$$

There, Pareto optimal solution[7] set is set to $1, c_{i}$ is the fitness of individual $i, u_{k(n)}$ is the $k$ target value of individual $\mathrm{i}, \mathrm{N}_{\text {rank }}$ is the number of individuals in the same level Pareto solution set. $\operatorname{rank}(\mathrm{i})$ is a random number between 0 and 1 :

$$
\mathrm{C}_{\mathrm{n}}=\max \left(\mathrm{c}_{\mathrm{n}}\right)-\mathrm{c}_{\mathrm{n}}(5)
$$

Where, $C_{n}$ is the cost value after the standardization of the $n$ colonial country, that is, degree of adaptation. The standardized $\operatorname{cost} \mathrm{C}_{\mathrm{n}}$ represents the energy of the colonial state. The colonies of the $\mathrm{n}$ colonial country can then be calculated:

$$
\mathrm{N}_{\mathrm{n}}=\mathrm{N}_{\text {col }} \mathrm{C}_{\mathrm{n}} / \sum_{\mathrm{i}=1}^{\mathrm{N}_{\mathrm{imp}}} \mathrm{C}_{\mathrm{i}}(6)
$$

$\mathrm{N}_{\text {col }}$ means the number of colonies, and $\mathrm{N}_{\mathrm{imp}}$ is the number of colonial countries.

\section{BRevolution and The Empire assimilated its colonies}

In this paper, ICA applications, we will set the revolution rate that the colonial countries will randomly change their position.

The assimilation process can be described as a continuation of the colonial state toward the empire until it is fully absorbed by the empire. As the following:

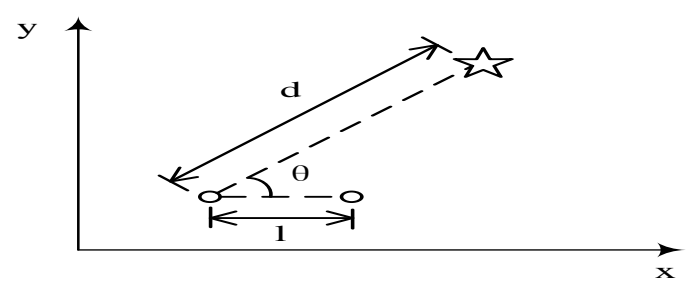

Fig.1 Colonies moving to the Empire

Here, the distance between the colonies and empires is d, and the colonies move randomly along the line of the empire for a distance l:

Where, $\beta \geq 1$. We take $\theta$ as follows:

$$
\mathrm{l} \sim \mathrm{U}(0, \beta \times d)(7)
$$

$$
\theta \sim U(-\gamma, \gamma)(8)
$$

\section{CCompetition}

The total value of an empire can be expressed as:

$$
\mathrm{F}_{\mathrm{n}}=\mathrm{c}_{\mathrm{n}}+\operatorname{cmeanf}_{\mathrm{n}(\mathrm{i})}(9)
$$

Where, $F_{n}$ is the total cost of the nth imperial bloc, $c_{n}$ is the cost of the nth imperial bloc, and $f_{n(i)}$ is the cost of the i colony of the $n$ imperial bloc. $\varepsilon$ represents the influence of the colony on the imperial group.Calculating the possibility, as the following :

$$
\mathrm{P}_{\mathrm{n}}=1-\frac{\mathrm{F}_{\mathrm{n}}}{\sum_{\mathrm{i}=1}^{N_{\mathrm{imp}}} \mathrm{F}_{\mathrm{i}}}(10)
$$

In order to classify the probabilities of the above-mentioned empires, the vector $\mathrm{P}$ is introduced: 


$$
\mathrm{P}=\left[\mathrm{P}_{1}, \mathrm{P}_{2}, \mathrm{P}_{3}, \ldots, \mathrm{P}_{\mathrm{N}_{\mathrm{imp}}}\right](11)
$$

The vector $\mathrm{M}$ follows a uniform distribution and has the same specifications as the vector $\mathrm{P}$ :

$$
\begin{gathered}
M=\left[M_{1}, M_{2}, M_{3}, \ldots, M_{N_{\text {imp }}}\right](12) \\
M_{i} \sim U(0,1) \\
Z=\left[P_{1}-M_{1}, P_{2}-M_{2}, P_{3}-M_{3}, \ldots, P_{N_{\text {imp }}}-M_{N_{\text {imp }}}\right]
\end{gathered}
$$

The largest element in the vector $\mathrm{Z}$ will occupy the colonies of the empires mentioned above.

\section{DConvergence}

At this point there are two cases the end of the algorithm, one for an empire left, the algorithm is the optimal solution; there is a case, reach the maximum number of iterations set .

\section{Experiment and result analysis}

\section{A Model parameter setting}

Here, select the Beijing Municipal Rail Transit Military Museum to Dongzhimen between the two stations of the bus routes, travel options are as follows:

Table 1 Optional route and their influencing factors

\begin{tabular}{ccccc}
\hline $\begin{array}{l}\text { Path } \\
\text { Selection }\end{array}$ & $\begin{array}{c}\text { In the car } \\
\text { time/min }\end{array}$ & $\begin{array}{c}\text { Transfer } \\
\text { times }\end{array}$ & $\begin{array}{c}\text { Transfer } \\
\text { distance/km }\end{array}$ & Congestion \\
\hline 1 & 31 & 1 & 0.8 & 1 \\
2 & 36 & 2 & 1.1 & 0.8 \\
3 & 44 & 3 & 1.5 & 0.7 \\
4 & 50 & 4 & 1.7 & 0.2 \\
5 & 55 & 5 & 1.8 & 0.3 \\
6 & 57 & 5 & 1.7 & 0.2 \\
7 & 48 & 6 & 1.5 & 0.4 \\
8 & 55 & 6 & 1.7 & 0.2 \\
9 & 60 & 6 & 1.9 & 0.3 \\
10 & 62 & 6 & 1.8 & 0.5 \\
\hline
\end{tabular}

\section{B ICA algorithm parameters setting}

Where, the initial number of ICA is 15 , the number of empires is $4, \beta=2$, the revolution rate is $0.3, \gamma=\pi / 4, \epsilon=0.1$ and the number of iterations is 100 .

\section{Results analysis}

There are four empires began to compete (where red star represents the path 1, yellow star represents the path 2 , blue star represents the path 3 , and green star represents the path 4,the rest circles are colonies): 


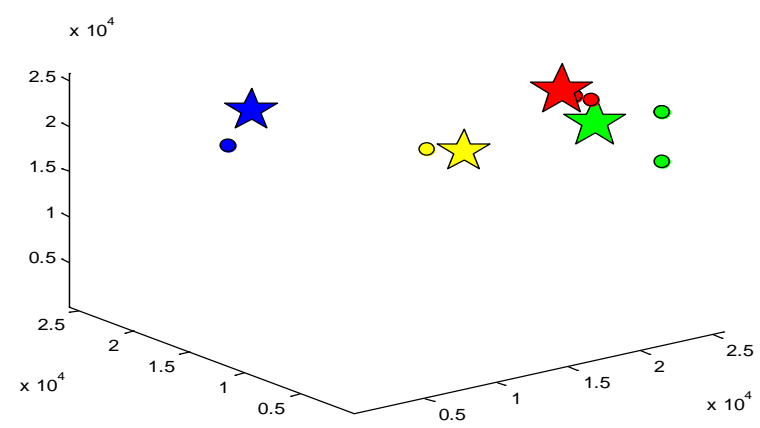

Fig.2 four path contention

As congestion is at its peak, 100 iterations are randomized to obtain the empire of final competition; the path 4 is the best route choice:

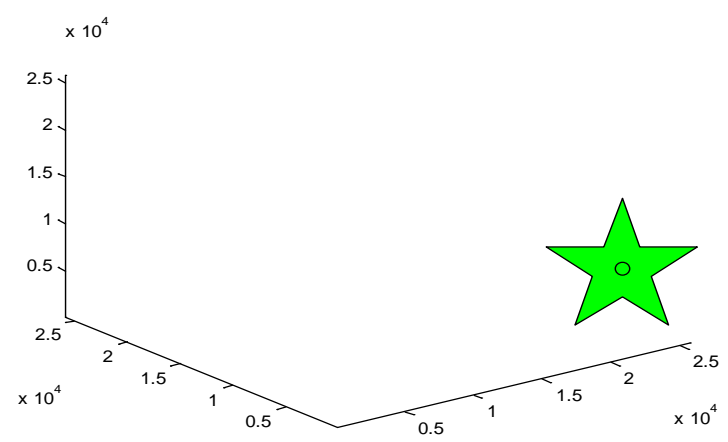

Fig.3Path 4 wins the competition

\section{Conclusion}

Based on the constraints of transfer times, this paper establishes the path selection model of urban rail transit with generalized travel cost as the objective function, and then optimizes the travel route by the ICA algorithm. The research contents and achievements of this paper can provide inspiration and reference for the model of other competitive problems solved by imperialism competitive algorithm.

\section{Acknowledgements}

This work was supported by the State Key Laboratory of Rail Traffic Control and Safety , BeijingJiao tongUniversity, andBeijing Technology and Business University Project Promotion Plan.

\section{References}

[1] Liu Kun. Based on ant colony algorithm for the track traffic path selection model and Application Research [D]. Beijing Jiao Tong University, 2011

[2] Cheng Bo, Yang Yu, Liu AiJun, Chen Wei, Xing Qingsong. Optimization of Transportation Route Selection Based on Genetic Simulated Annealing Algorithm [J]. Computer Integrated Manufacturing System, 2013, 04: 879-887

[3] Liu JianFeng, Sun FuLiang, Bai Yun, Xu Juan. Model and Algorithm of Passenger Routing in Urban Mass Transit [J]. Journal of Transportation Systems Engineering and, 2009, 02: 81-86 
[4] Atashpaz-Gargari and C. Lucas, "Imperialist competitive algorithm: An algorithm for optimization inspired by imperialistic competition," 2007 IEEE Congress on Evolutionary Computation, Singapore, 2007, pp. 4661-4667.

[5] Hao Yan. Non-probabilistic reliability analysis and optimization based on imperial competition algorithm [J]. Ji Lin University, 2014.

[6] Shao YongLiang, HuHao, Chang Jun. Structural Modal Parameter Identification Based on Imperial Competitive Algorithm [J]. Journal of Suzhou University of Science and Technology (Engineering \& Technology Edition), 2016, 01: 20-26.

[7] Hu Wang, Gary G. YEN, Zhang Xin. Multi-objective Particle Swarm Optimization Algorithm Based on Pareto Entropy [J] .Journal of Software, 2014, 05: 1025-1050. 